\title{
Peptidyl-Prolyl Cis-Trans Isomerase FKBP5
}

National Cancer Institute

\section{Source}

National Cancer Institute. Peptidyl-Prolyl Cis-Trans Isomerase FKBP5. NCI Thesaurus. Code C105831.

Peptidyl-prolyl cis-trans isomerase FKBP5 (457 aa, $\sim 51 \mathrm{kDa}$ ) is encoded by the human FKBP5 gene. This protein plays a role in the mediation of protein folding. 